\title{
MATERIAL DIDÁTICO NO CONTEXTO DA EAD: PLANEJAMENTO, ELABORAÇÃO E CARACTERÍSTICAS DOS MATERIAIS EDUCACIONAIS DOS CURSOS DE PÓS-GRADUAÇÃO DA ***.
}

\author{
SÃO LUÍS/MA JULHO/2018
}

\author{
Kátia Almeida Fonsêca - UEMA - katiafonseca.uemanet@gmail.com \\ Amilson Pimentel Batalha - CEUMA - a.milson@hotmail.com \\ Ilka Márcia Ribeiro de Souza Serra - UEMA - ilka.tt@gmail.com \\ Tipo: Relato de Experiência Inovadora (EI) \\ Categoria: Métodos e Tecnologias \\ Setor Educacional: EDUCAÇÃO MÉDIA E TECNOLÓGICA
}

\begin{abstract}
RESUMO
A EaD diferencia-se do ensino presencial por constituir um sistema tecnológico comunicacional sustentado por inovadoras concepções de ensino e aprendizagem. Com isso, o principal suporte na modalidade a distancia se constitui na disponibilização de materiais didáticos que possam guiar o estudo autoeducativo. Portanto, toma-se como objeto de estudo deste relato de experiência apresentar a concepção da elaboração do material didático nos cursos de Pós-Graduação a distância. Destaca-se conhecer os tipos mais utilizados e descrever o processo de produção dos relevantes materiais didáticos escolhidos para os cursos lato sensu da ${ }^{* *}$. Define-se como um levantamento bibliográfico, relatando sinteticamente uma experiência de construção coletiva do material didático que auxiliam os pós-graduandos no processo de ensino aprendizagem. A partir da experiência, pode-se aferir que 0 recurso didático possui um fluxo dialógico, que permite ao aluno compreender o que está sendo proposto na construção do conhecimento da disciplina. O estudo permite ainda um diálogo de construção com outras Instituições ofertantes de ensino a distancia, na busca de ampliar estudos dessa área e desta forma saber que outros princípios regem a elaboração destes produtos bem como também aprimorar o processo de elaboração e disponibilização desses materiais.
\end{abstract}

Palavras-chave: Planejamento, Material Didático, Pós-Graduações. 


\section{INTRODUÇÃO}

O inicio do século XXI vem sendo cada vez mais marcado pela diversificada difusão e investimento das tecnologias da informação e da comunicação (TICs) no campo educacional. Isto tem impulsionado uma gama de instituições de ensino superior a explorarem as possibilidades da educação na modalidade a distância. Os ambientes virtuais de ensino-aprendizagem tornam-se aos poucos os grandes responsáveis pelo novo paradigma da forma de compartilhar ensino e conhecimento. De acordo com Kenski (2003), a utilização das tecnologias tem influenciado todos os campos educacionais e encaminha as instituições para a adoção de uma cultura informática educacional, exigindo das mesmas uma reestruturação de suas ações educativas. Essa vertente, como observam Nova e Alves (2003), consiste no presente potencial transformador que implica em novas formas de aprendizagem e construção de saberes.

Com este crescimento, despontou a grande oferta de cursos latu sensu na modalidade $\mathrm{EaD}$, demandando do público interessado a procura por formas de ensino disponíveis e mais acessíveis. Isso pode ser explicado por dois fatores: o custo (mais baixo do que o dos cursos presenciais) e a flexibilidade para estudar a qualquer hora e em qualquer lugar. Neste contexto, salienta-se que em processos de ensino como a EaD é necessário que se haja um olhar atento ao material didático que é produzido. O material que é disponibilizado ao estudante, além de ser relevante fonte de informações dos conteúdos propostos é também utilizado como base para o desenvolvimento das atividades do curso.

Com isso,o objetivo desta pesquisa é apresentar o relato de experiência que é desenvolvido com a elaboração de material didático para os cursos de Pós-Graduação a distância da ${ }^{* * * * *}$. A pesquisa é eminentemente descritiva,com sustento bibliográfico, especificando a concepção da elaboração de material autoinstrutivo nos cursos das PósGraduação, descrevendo ainda os tipos mais utilizados e como acontece o processo de produção dos relevantes materiais didáticos escolhidos para os cursos lato sensu da $\star * * *$.

Para a compreensão do que se segue, o texto está organizado em quatro seções: introdução, breve histórico do *** que intermedia os cursos a distância da *** ,discussões teóricas sobre a elaboração de material didático para EAD, a metodologia,a sistemática dos materiais didáticos elaborados na Pós-graduação EaD da ${ }^{* * *}$ e por fim algumas considerações sobre o trabalho.

\section{CONTEXTO HISTÓRICO DO NÚCLEO DE TECNOLOGIAS PARA EDUCAÇÃO -}




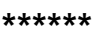

$A^{* * * * * * * * * * *}$ celebra este ano de 2018, 20 anos de ensino na modalidade de Educação a distância. No ano de $1998 a^{* * * *}$ criava o Programa para formação de professores leigos que atuavam na rede pública de ensino do estado do Maranhão. Assim, nascia o Núcleo de Educação a Distância (Nead), em que no ano de 2008 passou a denominarse Núcleo de Tecnologias para Educação- ${ }^{* * * *}$. Atualmente é o único Núcleo que intermedia os cursos a distância da referida instituição, com um quadro de 200 colaboradores que se tornam responsáveis pela concepção, intermediação, gestão, avaliação e difusão de projetos educacionais na modalidade a distância, além de prestar suporte tecnológico à educação presencial da ${ }^{* \star * * *}$.Foi em outubro de 2001 através da Portaria $n^{0} 2.216$ que $a^{* * * *}$ obtve 0 credenciamento para oferta do curso de Licenciatura em Magistério das Séries Iniciais do Ensino Fundamental, tornando-se a 8ª IES pública do Brasil e a pioneira do Nordeste nesta anuência, fato que Ihe propiciou a habilitação para oferta de outros cursos superiores dentro desta modalidade.

Nestas duas décadas $0^{* * *}$ através do ensino $\mathrm{EaD}$, se mostra um caminho factível na luta contra os impactos da exclusão social, ao passo que oportuniza acesso democrático ao conhecimento e consequente formação do cidadão maranhense.

\section{MATERIAIS DIDÁTICOS PARA EAD}

No princípio, o homem buscava registrar sua história e transmitir informações através de símbolos, marcas em pedras, paredes e árvores. Era através desta linguagem rudimentar que o homem tentava se comunicar. Com o passar do tempo, o processo comunicacional foi evoluindo e novas ferramentas eram criadas.

No caso da Educação a Distância são utilizados duas principais comunicações denominadas de síncronas (relação que acontece simultaneamente) e assíncronas (não há conexão dos envolvidos ao mesmo tempo).Neste contexto, o processo comunicacional da aprendizagem é estabelecido por meio de instrumentos pedagógicos que viabilizem essa interlocução,os chamados materiais didáticos.

No ensino a distância os materiais didáticos configuram-se um aspecto fundamental do planejamento e gestão de cursos EaD .Estes recursos têm um caráter de instrumentar, orientar e informar um caminho que pode ser seguido na busca pela obtenção de determinados conhecimentos. No estudo de Neder (2003), este recurso deve ser pensado e concebido no interior de um projeto pedagógico e de uma proposta curricular definida claramente. Ainda segundo o autor (2003), é o instrumento para diálogo 
permanente entre alunos, professores e o conhecimento, e é por isso que que o material didático precisa estar situado nos projetos pedagógicos de $\mathrm{EaD}$, assim como deve manter uma coerência interna com os pressupostos pedagógicos e respectivas plataformas curriculares. De acordo com o MEC (2007) os materiais didáticos dos cursos ofertados na modalidade a distância "[...] deve estar pautado de acordo com os princípios epistemológicos, metodológicos e políticos definidos no projeto pedagógico, de modo a facilitar a construção do conhecimento e mediar a interlocução entre estudante e professor [...]". Para Oliveira (2004), é necessário que o material didático esteja de acordo com o projeto pedagógico do curso, e com a proposta curricular da disciplina.

Assim, para que se obtenha sucesso nesse processo é preciso que se tenha cuidado com a utilização da linguagem adotada no material online. "O material didático para EAD se configura como um conjunto de mídias (impresso, audiovisual e informático) no qual os conteúdos apresentam-se de forma dialógica e contextualizada favorecendo uma aprendizagem significativa."(FLEMING,2004,p. 23). Então, fica evidente que o material didático desenhado para a EaD precisa favorecer o desenvolvimento da aprendizagem significativa dos estudantes.

\section{TESSITURA METODOLÓGICA}

Para a realização deste trabalho, foi definida uma metodologia constituída pelo relato de experiência. A experiência é desenvolvida no Núcleo de Tecnologias Educacionais da $* * * * *$, e o relato encontra-se delimitado apenas aos cursos de Pós-Graduação. Para tanto, esta é uma pesquisa documental, eminentemente descritiva, relatando sinteticamente uma experiência de construção coletiva dos materiais didáticos que auxiliam os pós-graduandos no processo de ensino aprendizagem.Após a organização dos dados para a escrita do relato de experiência, buscou-se por dados qualitativos desenvolvidos por outras universidades. Para um aprofundamento do conhecimento, o acesso às leituras de textos diversos, pesquisas transversais, são fundamentais (PEREIRA;ALVES 2016). As bibliotecas digitais ampliam estas alternativas (TRIMER, 2011).

Neste caso, foi realizada um levantamento bibliográfico nos anais de dois eventos brasileiros a respeito de educação a distância: ESUD e CIAED, dos anos de 2013 até 2017. O objetivo desta, foi procurar por panoramas sobre a elaboração de materiais didáticos na modalidade EAD, como vem sendo empregada em cursos da área da educação em particular. 


\section{SISTEMATIZAÇÃO DE MATERIAIS DIDÁTICOS DA PÓS-GRADUAÇÃO EaD DA} $\star * \star * *$

A ***atualmente conta com a oferta de 5 cursos de Graduações, 4 Pós-Graduações, 12 Técnicos, 3 Tecnólogos e 24 cursos livres. Impulsionados pela ampla difusão das tecnologias, a ${ }^{* \star * *}$ passa atualmente a abranger com cursos online em 36 regiões do estado do Maranhão. E considerando essa ampla abrangência é preciso que se tenha atento olhar ao processo que envolve a produção dos materiais didáticos, pois na EaD é a principal ferramenta de quem ensina e quem aprende. Estes recursos devem estar em consonância com as diretrizes nacionais, principalmente porque é pensado numa perspectiva de integrar diversas culturas.

Neste sentido, a ${ }^{* * * *}$ por meio do Núcleo de Tecnologias, no cumprimento de sua missão legal de assegurar a qualidade na elaboração destes produtos, busca elaborar os materiais pedagógicos na respectiva dinâmica apresentada na figura a seguir.

Imagem 1:Mediação Pedagógica

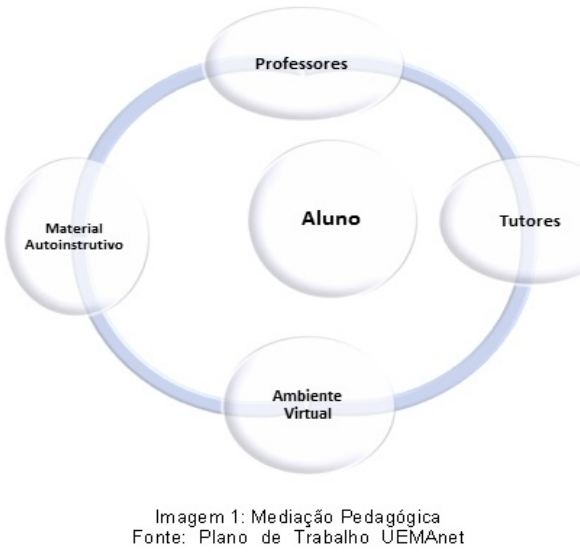

A imagem ilustra a importância dada ao processo de elaboração dos materiais, considerando, sobretudo, uma forma de interação adequada entre os componentes envolvidos em cursos nessa modalidade, estando assim voltado para o centro que é o aluno aprendente. Sobre este aspecto Fiorentini (2000) nos coloca que é fundamental que os professores em EAD, ao elaborar os materiais didáticos, estruturem seus 
discursos considerando os interesses e expectativas dos seus alunos.

Os critérios definidos na elaboração dos materiais de cada disciplina dos cursos de PósGraduação da ${ }^{* * * *}$ a distância têm inicio após a definição do projeto do curso, onde este é repassado ao professor contratado e logo a seguir direcionado ao setor de Designer Educacional (DE), sendo assim orientado quanto aos procedimentos didáticos e metodológicos da produção do material autoinstrutivo de cada disciplina. Para produzir cada material que compõe a estrutura organizacional da disciplina, o professor -autor escolhido dispõe de subsídios de orientação por uma equipe de Designers Educacionais (DE). Romiszowski (2011) corrobora apontando este profissional como uma atividade à luz de princípios de comunicação, aprendizagem e ensino para melhoria de materiais e ambientes de aprendizagem. Eles são os corresponsáveis no acompanhamento e direcionamento das ações do professor. É uma equipe multidisciplinar, composta por: designer pedagógico, designer de vídeo, cinegrafista, editor, videografista, revisor de texto entre outros que darão suporte ao professor-autor, tanto nas questões técnicas, quanto pedagógicas.

Assim que o professor (a) é apresentado (a), ele (a) passa a ter um suporte pedagógico no setor DE onde são ministradas oficinas pedagógicas para a elaboração dos materiais didáticos que irão ser utilizados no processo ensino e aprendizagem da disciplina. As oficinas, que tem um caráter de formação, ministradas por profissionais da área, com duração de $2 \mathrm{~h}$, tem como principal objetivo capacitar o profissional para atuar como docente nesta modalidade Ead, onde são apresentadas ferramentas e dicas que auxiliem o professor, especialista na área, a escrever o material de maneira dialógica e autodidática. São 4 as oficinas, sendo estas nomeadas como "Oficina de "Planejamento e Fórum", "Câmera e Ação", "Linguagem" e "Avaliação". A de Planejamento e Fórum tem como objetivo orientar o professor na forma de planejar e elaborar bons fóruns e atividades avaliativas. A de Câmera e Ação trabalha aspectos da rotina de gravar aulas e as diferentes formas de se apresentar diante das câmeras. A oficina de Linguagem auxilia o (a) professor (a) na produção do seu material escrito e digital (E-book). E por fim a de Avaliação que prevê a formação do professor no que tange a elaborar questões significativas e adequadas ao conhecimento da disciplina. O professor (a) conta ainda com o auxílio de diferentes profissionais, sendo eles de acompanhamento, como o Designer Pedagógico que orienta o professor/a até a conclusão do processo ensinoaprendizagem da disciplina.

Os principais materiais didáticos escolhidos no âmbito dos cursos de Pós-Graduação a distância na **** são: o Caderno de Estudos ou E-book de cada disciplina, o Slide com Conteúdo, o Plano de Ensino, o Fórum e Atividade, o Roteiro de Estudo, os Slides de 
Capacitação dos Tutores e Alunos, as Videoaulas, os Podcats, a escolha do Material Complementar e por fim as Avaliações. As características de alguns dos principais produtos veremos adiante.

Neste aspecto, a Instituição vem fazendo um bom uso das diferentes mídias em EaD. Vejamos a seguir na imagem baixo como se dá a concepção na produção metodológica dos materiais didáticos disciplina.

Imagem 2: Sistematização de Elaboração dos Materiais Didáticos

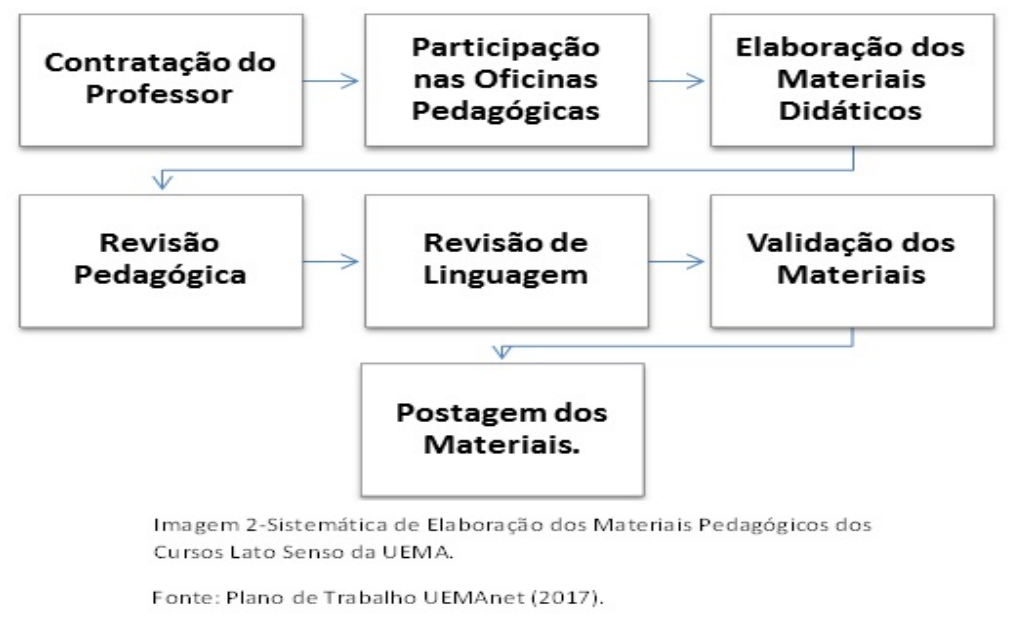

A imagem acima demonstra com relevância a sistematização organizada e atenta na produção do material autoinstrutivo. O professor (a) responsável pela disciplina é convidado pela coordenação do curso, onde após sua contratação é direcionado ao setor de Designer Educacional. Assim que o professor é capacitado nas oficinas ele fica com a missão de elaborar os materiais a partir da ementa descrita no projeto do curso. Quando o material está em sua fase de desenvolvimento o professor encaminha para a equipe do setor. A partir daí é feito a revisão pedagógica e de conteúdo. A revisão pedagógica é importante para que o autor/autora recupere expressões ou partes do texto que não ficam claras, ou que precisam ser retomadas e aprofundadas. Feito esse procedimento e ajustado, o material é enviado à equipe de revisão. A revisão de linguagem e ortografia caminha para adequar o conteúdo aos parâmetros descritos pela instituição. Assim que é feita a articulação entre forma e conteúdo, e não tendo mais nada a ser modificado pelo autor do conteúdo e pela Equipe de Designers, o material é encaminhado para sua fase final de validação e sua posterior postagem no ambiente virtual de aprendizagem. Vejamos como se dá as caraterísticas de alguns dos relevantes materiais escolhidos para a estrutura destes cursos. 


\subsection{Plano de Ensino}

É o principal instrumento de identificação da disciplina. Elemento estruturante da ementa e dos conteúdos programáticos a serem estudados. Em via de regra é a representação do que ensinar (Objetivos), o que aprender (Conteúdos), como desenvolver (Metodologia), com o que ensinar (Recursos) e o que avaliar (Avaliações).

\subsection{Caderno de Estudos ou E-book}

Material base para o estudo do aluno. Neste produto o professor é orientado a produzir um material que adote uma linguagem e metodologia típica da $\mathrm{EaD}$, permitindo assim uma qualidade e interação com os estudantes. A hipertextualidade, intertextualidade, multimodalidade, dialogismo e várias outras noções tornam-se fundamentais.

\subsection{Videoaulas}

De uma maneira geral as Videoaulas são consideradas importantes instrumentos na construção de conhecimentos dos educandos inseridos na EaD. Elas complementam as ideias e estudos apresentados no decorrer da disciplina. As Videosaulas produzidas no Núcleo de Tecnologias da $^{* * * *}$ são concebidas em linhas por apresentação do conteúdo e de tópicos mais importantes do conteúdo da disciplina. Em média, também precisam ser dinâmicas, criando uma sensação de proximidade com o aluno.Dentre estas, são sugeridas gravações de exposição didática, entrevistas, documentários, dentre outros, assim como também a utilização de matérias interessantes pré-produzida por outros autores, levando sempre em consideração os direitos autorias.

\subsection{Slide com Conteúdo}

Este é um material pedagógico também adotado no projeto dos cursos. É um recurso adotado quando não há o caderno de estudos ou e-book. É também um material a ser escrito pelo professor-autor, tendo a responsabilidade de estruturar um tipo de apresentação que expresse os conteúdos da disciplina a partir da ementa. O conteúdo é apresentado em forma de Slides e deve compor de forma resumida e também hipertextual o conteúdo programático da disciplina.

\subsection{Fórum e Atividade}

$\mathrm{Na}$ oficina de "Planejamento", o professor é orientado a planejar e elaborar diferentes atividades assíncronas. Os Fóruns e Atividades são mantidos com o intuito de aprimorar 
os conhecimentos construídos pelo aluno em cada disciplina. O professor é orientado a produzir questões que utilizem a aprendizagem colaborativa, que despertem o leitor para o aprendizado de uma nova leitura e que esta permita a avaliação contínua da aprendizagem, uma vez que é o espaço onde os participantes constroem e expõem suas opiniões sobre o tema abordado, assimilando assim o conteúdo e gerando novos conhecimentos.

\subsection{Avaliações}

O formato avaliativo dos cursos da Pós-Graduação é composto por 3 avaliações. Avaliação de $1^{\text {a }}$ chamada, $2^{\text {a }}$ chamada e do plano de recuperação. As avaliações de $1^{\text {a }}$ chamada e de recuperação precisam contemplar 4 questões objetivas e 3 discursivas, já a de $2^{\mathrm{a}}$ são abordados apenas questões discursivas. Além destas, são utilizados também como formas avaliativas as apresentações,seminários, estudos de casos,dentre outros.

\section{ALGUMAS CONSIDERAÇÕES}

No inicio do relato apresentamos como objetivo a descrição do relato de experiência no sentido de discriminar como é elaborado e sistematizado os materiais didáticos para os cursos de Pós-Graduação. A partir do momento que a EaD cresce no cenário educacional, novas propostas, metodologias e modelos de ferramentas digitais se fazem necessário discutir e aplicar, para que auxiliem os alunos na sua forma de estudar .Por isso, acreditamos que os resultados aqui descritos representam a abertura de outras vertentes, entendendo que pesquisam como estas devem ser ampliadas no sentido de apresentar novas práticas metodológicas como estas em que são elaborados materiais didáticos para o ensino a distancia.

Nesse sentido, o texto descreve a atenção que é dada a elaboração dos materiais que devem compor o ambiente dos cursos de Pós, demonstrando assim a supervalorização dos processos.

Deste modo, a Instituição em questão busca ainda estudar e conhecer outros novos meios de comunicação e de disponibilização destes materiais disponíveis na grande rede, saber quais outros princípios regem a elaboração destes produtos, os critérios que são estabelecidos, assim como também aprimorar o processo de reelaboração e disponibilização desses materiais.

\section{REFERÊNCIAS}


ALVES, L; NOVA, C. Educação a distância: uma nova concepção de aprendizado e interatividade.São Paulo: Futura, 2003.

BRASIL. Ministério da Educação. Secretaria de Educação a Distância. Referenciais de qualidade para a educação superior a distância. Brasília, p.13.2007.

BRASIL. Ministério da Educação. Portaria no 2.216, de 11 de outubro de 2001. Credencia a Universidade Estadual do Maranhão para oferta de cursos a distância, Brasília, DF, 2001.

FLEMING, D. M. "Desenvolvimento de Material Didático para a Educação a Distância no contexto da Educação Matemática". São Paulo, p. 23. 2004. Disponível em: < www.abed.org.br/congresso2012/anais/104c.pdf> Acesso em: 05 abr. 2018.

NEDER, L. Curso de Extensão em Elaboração de Material Didático Impresso. Ceará -:Universidade Estadual do Ceará, 2003.

KENSKI, V. M. Tecnologias e ensino presencial e a distância. 2. ed. Campinas, SP: Papirus, 2003.

OLIVEIRA,Q.Z.T. A construção do material didático em EaD: uma experiência de aprender fazendo, através da ação, do conhecimento e da afetividade. In: $11^{\text {o Seminário }}$ nacional ABED de educação à distância, Campo Grande-MS, 2004.Disponível em:<www.abed.org.br/congresso2004/por/htm/038-TC-B2.htm> Acesso em: 04 abril.2018.

PEREIRA. A. M. A; ALVES. T. P. Produção e uso de recursos educacionais abertos na Uab. In: Congresso Brasileiro de Educação a Distância-ESUD. Minas Gerais. Anais... Minas Gerais. 2016.

TRIMER, R. Livro e Apostilas na educação superior à distância. In: LITTO, Frederico; FORMIGA, Marcos. Educação a distância: o Estado da arte. 2. ed. SãoPaulo: Pearson, 2011. Cap. 36. p. 311-318.

ROMISZOWSKI, A. Design Instrucional: O que é? Quem faz? Como fazem?Curso Online de Design Instrucional. Aquifolium Educacional. Disponível em:< esud2014. nute.ufsc.br/anais-esud2014/files/pdf/127093.pdf> .Acesso em: 1 maio.2018. 